\title{
Diffusion Model for Describing the Regional Spread of Huanglongbing from First- Reported Outbreaks and Basing an Area Wide Disease Management Strategy
}

\author{
J. L. Flores-Sánchez, Programa de Fitosanidad, Campus Montecillo, Colegio de Postgraduados, Texcoco, Mexico, C.P. 56230; G. Mora-Aguilera, \\ Programa de Fitosanidad, Campus Montecillo, Colegio de Postgraduados, Texcoco, Mexico, C.P. 56230; and LANREF-Colegio de Postgra- \\ duados, Campus Montecillo, Texcoco, Mexico, C.P. 56230; E. Loeza-Kuk, Centro de Investigación Regional Sureste, Instituto Nacional de \\ Investigaciones Forestales, Agrícolas y Pecuarias, Mococha, Yucatán, Mexico, C.P. 97454; J. I. López-Arroyo, Campo Experimental \\ General Terán, Instituto Nacional de Investigaciones Forestales, Agrícolas y Pecuarias, Nuevo León, Mexico, C.P. 67413; M. A. Gutiérrez- \\ Espinosa, Programa de Fruticultura, Campus Montecillo, Colegio de Postgraduados, Texcoco, Mexico, C.P. 56230; J. J. Velázquez- \\ Monreal, Campo Experimental Tecomán, Instituto Nacional de Investigaciones Forestales, Agrícolas y Pecuarias, Colima, Mexico, C.P. \\ 28100; S. Domínguez-Monge, Programa de Fitosanidad, Campus Montecillo, Colegio de Postgraduados, Texcoco, Mexico, C.P. 56230; \\ R. B. Bassanezi, FUNDECITRUS, C.P. 391, 14801-970, Araraquara, São Paulo, Brasil; G. Acevedo-Sánchez, LANREF-Colegio de Post- \\ graduados, Campus Montecillo, Texcoco, Mexico, C.P. 56230; and P. Robles-García, SENASICA-Dirección General de Sanidad Vegetal, \\ Coyoacán, Mexico, C.P. 04100
}

\begin{abstract}
Huanglongbing (HLB), a recent worldwide spreading disease on citrus, was detected in July 2009 in Yucatan State of Mexico. The objective of this study was to evaluate the fit of diffusion and classic disease gradient models to large-scale HLB spatial data originated from initial foci to improve sampling, monitoring, and control strategies for Diaphorina citri, vector of Candidatus Liberibacter asiaticus (CLas), putative agent of HLB. Four transect routes were selected: Yuc-1, Yuc-2, QRoo-1, and QRoo-2, based on the directionality of the prevailing winds and foci location of HLB infected plants. In these routes, 35 sites, 5 to $20 \mathrm{~km}$ apart, were selected for monthly evaluation during a 12-month period. A 10-insect sample and disease incidence and severity of HLB, further confirmed by PCR, were assessed per site. Mexican lime was more vulnerable $(67.5 \%)$ than sweet orange $(14 \%)$. Also, leaf symptoms were

mostly found with homogeneous distribution but rarely reaching $100 \%$ of the tree canopy during the 12-month period. The diffusion model provided the best fit among the family of time-gradient curves $\left(r^{2}=0.90\right.$ to 0.99 ) due to the flexibility of a three-parameter model. The gradients were well conformed to the model in a 25 to $82.6 \mathrm{~km}$ range, having the east-west direction the longest effect. Yuc-2 and QRoo-2 transects showed 82.6 and $43.9 \mathrm{~km}$ gradients with a diffusion coefficient (Do) of 0.15 and 0.09 , respectively. This study constitutes the first quantitative evidence of the regional spread of $C$ Las from a single focus and the application of a flexible model that improved the fit and allowed to better compare different gradients. These results are useful to determine the size of Regional Areas of Diaphorina citri Control (ARCO), a management program currently implemented in Mexico to combat HLB.
\end{abstract}

Huanglongbing (HLB) is one of the major threats to the sustainable production of citrus worldwide (Bassanezi et al. 2013b; FloresSánchez et al. 2015; Robles-González et al. 2013; Salcedo et al. 2010; Santivañez et al. 2014). At present, three species of Candidatus Liberibacter have been associated with HLB: $C a$. L. asiaticus, $C a$. L. americanus, and $\mathrm{Ca}$. L. africanus (Gottwald 2010; Santivañez et al. 2014). In Mexico, $C a$. L. asiaticus (CLas) was detected for the first time in July and August 2009 at Tizimin (Yucatan State) and Lázaro Cardenas (Quintana Roo State), respectively (Salcedo et al. 2010; Trujillo-Arriaga 2010). CLas is vectored and transmitted by Asian citrus psyllid Diaphorina citri Kuwayama (Hemiptera: Liviidae) (DC) (Hall et al. 2013; Torres-Pacheco et al. 2013). For managing the CLas vector, Bassanezi et al. (2013b) showed that control practices applied at the regional level resulted in improved HLB control compared with local (orchard) practices. However, the biological and epidemiological criteria to define the size and location of an area-wide management have not been formally addressed. Bové (2012) empirically suggested 500 ha as an appropriate area-wide size to manage HLB in Brazil. Nonetheless, Brazilian orchards at the major citrus-producing states are usually large enough, which facilitates implementation of regional control, though the criteria lack scientific support. In Florida, U.S.A. citrus health management areas (CHMAs), ranging from 4,000 to 20,000 ha, have been recommended as an important strategy

Corresponding author: G. Mora-Aguilera; E-mail: morag @ colpos.mx

Accepted for publication 3 March 2017.

This article is in the public domain and not copyrightable. It may be freely reprinted with customary crediting of the source. The American Phytopathological Society, 2017. to reduce HLB spread (Rogers et al. 2011). Its primary goal is to coordinate growers' efforts to control DC to lower the vector's population size for reducing the spread of primary and secondary inoculum.

In Mexico, a national emergency plan for $C$ Las prevention and risk mitigation was established in 2008 for more than 500,000 ha in 23 citrus-producing states (Trujillo-Arriaga 2010). Upon entry, extensive foliar tissue and DC sampling for CLas detection, diseased tree removal, and vector control has been carried out by phytosanitary officials at the national level (SENASICA 2012, 2017). The fast $C$ Las spreading on Key lime in the Mexican Pacific (Mora-Aguilera et al. 2014b; Robles-González et al. 2013) prompted development of the ARCO approach, a regional comprehensive program for DC control funded and coordinated by the government (Mora-Aguilera et al. 2014c; SENASICA 2012, 2016). The rationale for such an approach was the analysis of disease gradients from initial foci, mostly targeting a large scale, to establish scientific criteria for a regional management. Previous attempts on a quarantined disease, coconut lethal yellowing (CLY), long range gradient studies in the Yucatan Peninsula, complemented with intraplot spatial patterns, were critical to optimize sampling for eradication purposes and to define width of belts and interbelt distances for phytosanitary inspection (GóngoraCanul et al. 2004; Mora-Aguilera et al. 2017; Pérez-Hernández et al. 2004). In that study, the Gregory and negative exponential models fairly well fitted CLY gradients. These nonflexible empiricallyderived models fit the directional disease spatial dependence from a focus, resulting in the decline of disease intensity with increasing distance (Campbell and Madden 1990). For a newly introduced disease, shape gradients are changing in time and space; thus, the use of these models is restricted. On the other hand, the flexible diffusion models, used in ecology to study animal migration, are more feasible to fit a family of curves enhancing the analytical capabilities and applications (Murray 1989; Okubo 1980). 
In Mexico, CLas has been confirmed in trees and/or in DC specimens in 23 citrus growing states (SENASICA 2017). Despite widespread HLB, there are some states, such as Coahuila and Sonora, where only CLas-positive DC has been detected, while in most states of central Mexico and the gulf, where approximately $80 \%$ of the citrus is produced, HLB is regionally restricted to foci. Therefore, surveillance, sampling, and regional management must be reinforced to reduce the risk of introduction, establishment, and spread of $C$ Las. Thus, this study aimed to characterize disease gradients of the primary HLB outbreaks in the Yucatan Peninsula via fitting classic empirical and diffusion gradient models to large-scale monitoring of HLB. Quantitative knowledge on the disease gradients is of use to improve sampling, monitoring, and area-wide management strategies targeting DC control in order to mitigate the disease impact to the Mexican citrus industry and production.

\section{Materials and Methods}

Transect routes. Four transect routes were established in the Yucatan Peninsula: Yuc-1 and Yuc-2 in Yucatan State and QRoo-1 and QRoo-2 in Quintana Roo State (Fig. 1). With the exception of Yuc-2, transects started from the first recorded HLB-infected plants (foci) and the directions were determined considering the following scenarios as risk factors for DC attraction: i) routes of prevailing winds, ii) highways with high citrus products mobility, and iii) availability of citrus orchards adjacent to highways. Twenty-four sites were randomly selected for inspection in Yucatan State and 11 for inspection in Quintana Roo State, at variable distances among then. In the region, $70 \%$ of the selected areas were rural groves $\leq 0.5$ ha. The rest were commercial citrus groves $\leq 30$ ha.

The transect routes in Yucatan State were defined as follows (Fig. 1): Yuc-1: from El Cuyo (focus 1) to Popolnah in Tizimin county, north-south direction and $60 \mathrm{~km}$ in length. Yuc-2: from Xcan, Chemax county to Kantunil, Kantunil county, east-west direction and $150 \mathrm{~km}$ in length. The transect routes in Quintana Roo State were: QRoo-1: from Chiquila (focus 2), Lazaro Cardenas county to San Pedro, Benito Juarez county, north-south direction and $60 \mathrm{~km}$ in length. QRoo-2: from Cancun (focus 3) to Esperanza in Benito Juarez county, eastwest direction and $80 \mathrm{~km}$ in length.

The methodology followed the LYC disease gradient research that established the directional dispersion effect of north-south and eastwest transects (Góngora-Canul et al. 2004). The data for the four gradients were analyzed using the Geostatistical Analysis tool of ESRI ArcMap 10.0. Voronoi monthly maps were generated from March 2010 to February 2011. For each gradient, a buffer area $2.5 \mathrm{~km}$ in length was defined to represent HLB incidence.

Sample collection and disease assessment. The study was carried out during a year, from March 2010 to February 2011. Collection of plant and insect samples for molecular identification of $C$ Las, as well as the recording of HLB disease data, were performed monthly in all sites at each transect route. On each site, trees were inspected for typical HLB symptoms (Esquivel-Chávez et al. 2012; Robles-González et al. 2013). Leaf samples were taken from a minimum of five HLBsymptomatic trees for CLas confirmation. Each sample was composed of four leaves collected from each cardinal point of the tree canopy. Five- to 10-specimen composite samples were collected from five symptomatic and/or asymptomatic trees per area. Preference was given to diseased trees when present. The citrus species found in the region, often as crop mixture, were Citrus aurantifolia (Christm.) Swingle, C. latifolia Tanaka, C. volkameriana Ten. \& Pasq., C. sinensis (L.) Osbeck, $C$. aurantium L., and $C$. reticulata Blanco. HLB incidence represents the proportion of $C$ Las-positive plants in the sample. HLB severity was determined by plastic cube $(50 \times 50 \times 50 \mathrm{~cm})$. On each cardinal point $(s)$, severity represented the proportion of HLBsymptomatic branches inside the cube. The cube was placed on the outer canopy at a height of approximately $1.70 \mathrm{~m}$ of the tree. The percent severity $\left(\% \mathrm{Sev}_{t}\right)$ per tree was calculated as the mean severity across the cardinal points: $\% \mathrm{Sev}_{t}=\sum\left(\operatorname{Sev}_{s}\right) / 4$, where $t=$ time in months and $s=1$ to 4 (referring as follows: $1=$ north, $2=$ south, $3=$ east, and $4=$ west canopy evaluation).

Molecular analysis and diagnosis. Plant $(n=2,500)$ and insect $(n=550)$ composite samples were analyzed in the laboratory of the
INIFAP-CE Mococha, Yucatan State, and in COLPOS-Montecillo, Mexico State. DNA of plant samples was isolated using the cetyl trimethylammonium bromide (CTAB) method (Dellaporta et al. 1983). Insects were processed with the DNeasy Blood \& Tissue Kit (Qiagen, Valencia, CA). CLas detection was performed by conventional PCR as previously described by Li et al. (2007).

Factors affecting HLB severity. The nonparametric KruskalWallis test was used to analyze the single effect of citrus species, cardinal points on tree canopy, sampling date, and differences on transect routes on HLB severity. When a significant effect $(P=$ 0.05 ) was found for a factor, means were separated based on Tukey test of rank data $(P=0.05)$ in SASV9.0. The number of positive $C$ Las DC samples integrated by transect route and by assessment date were also tested to analyze the effect of positive-DC on the HLB gradients.

Disease gradients analysis. HLB incidence per month was plotted against distance from the inoculum source (initial outbreak) to visualize the disease gradient shape. The traditional disease gradient models were fitted to the data, including the negative exponential $[\ln (y)=a-b \ln (x)]$ and the Gregory model $[\ln (y)=a \ln (x)-b]$ in its logarithmic form; where $y$ represents an incidence value, $x$ represents distance, $a$ is the incidence amount in the outbreak, and $b$ is a dispersion rate parameter (Campbell and Madden 1990).

Additionally, an adaptation of a one-dimensional non stationary wave model, a particular case of the diffusion model, was also fitted to the data. Such an approach was previously used to model intraplot gradients of a vector-borne virus disease (Mora-Aguilera 1995). The model is given by:

$$
\frac{\partial n}{\partial t}=D o \frac{\partial}{\partial x}\left[\left(\frac{n}{n_{0}}\right)^{m} \frac{\partial n}{\partial x}\right]
$$

where $n$ is the parameter of population density in a given time $t$ and $x$ is the distance from the initial outbreak, $D o$ is the coefficient of diffusion, $m$ determines the curve shape, which should be greater than 0 ; Do, $m$, and $n_{0}$ are positive constants and have biological interpretations (Murray 1989; Okubo 1980). The model was fitted to the data using a program written for the nonderivative method DUD of PROC NLIN in SAS 9.0 (Mora-Aguilera 1995).

The statistical significance $P>\mathrm{F}$ and the coefficient of determination $\left(r^{2}\right)$ of a linear regression of predicted versus observed data were used to assess the goodness of fit and select the best model fitted to gradients. Additionally, $t$ tests were used to test the null hypotheses of intercept $(a)=0$, and slope $(b)=1$, both at $5 \%$ probability.

Temporal analysis of gradients and regional spread. In order to determine the disease progress rate, the HLB incidence $(y \neq$ $0 \%$ ) recorded at the longest distance per transect/month, accumulated over time, was fitted to a flexible two-parameter Weibull model $\left(y=1-[t / b]^{c}\right)$, using the nonderivative method DUD of PROC NLIN of SAS 9.0 (Jesús et al. 2004); in this model, $y$ represents the proportion of disease incidence, $t$ is time in months, $b$ is the epidemic rate parameter estimated in its inverse form $(1 / b)$, and $c$ is the curve shape parameter (Mora-Aguilera et al. 1996; Pennypacker et al. 1980). Since the maximum accumulated disease incidence $\left(y_{\max }\right)$ was lower than $20 \%$, the model fit was improved by scaling the epidemic curves using a multiplicative factor $(s)$ for each incidence curve value $\left(y_{i}\right)$ calculated as $y_{j}=\left(y_{i}\right) s_{i}$, where $s_{i}$ is the scaling factor specific to the transect- $i$ curve obtained as $s_{i}=\ln \left(100-Y_{\max }\right)$ (G. Mora-Aguilera, unpublished). Convergence, error of parameters $(b, c)$, and $R^{2}$ value were used to determine goodness of fit. The adjusted $R^{2}$ was obtained via linear regression analysis of the model-predicted versus actual data. The temporal HLB occurrence at Yucatan and Quintana Roo states were estimated with the number of $C$ Las-positive trees reported by the Mexican Phytosanitary Program against HLB from July 2009 to March 2016 (SENASICA 2016).

\section{Results}

Severity of HLB. Considering the four transects, the mean HLB severity was significantly higher $(P<0.05)$ in the sour citrus species $($ Key lime,$C$. aurantifolia $=67.5 \%$; Persian lime, $C$. latifolia $=51.5 \%)$ 
than in the sweet citrus species (mandarin, $C$. reticulata $=15.3 \%$; sweet orange $C$. sinensis $=14 \%$ ) (Fig. 2A). C. sinensis, represented by $30 \%$ of the evaluated citrus trees, showed the lowest percentage severity among six citrus species found on transects $(P=0.05)$. HLB severity was uniform on tree canopy with no differences among cardinal points (north $=45.7 \%$, south $=45 \%$, east $=46.1 \%$, and west $=46.4 \%$ ) (Tukey, $P \leq 0.05$ ) (Fig. 2B). HLB severity ranged from $64.1 \%$ in
May to $29.7 \%$ in September (Fig. 2C). Temporal intensity of HLB symptoms was oscillatory with apparent cycles of 3 to 4 months, particularly in sour citrus species, which exhibited a more intensive sprouting than the sweet citrus species. Average HLB severity related to transects were higher in QRoo-1 and QRoo-2 with $54.7 \%$ and $47.9 \%$, than Yuc-1 and Yuc-2 with $30.7 \%$ and $22.5 \%$, respectively $(P=0.05)$ (Fig. 2D).
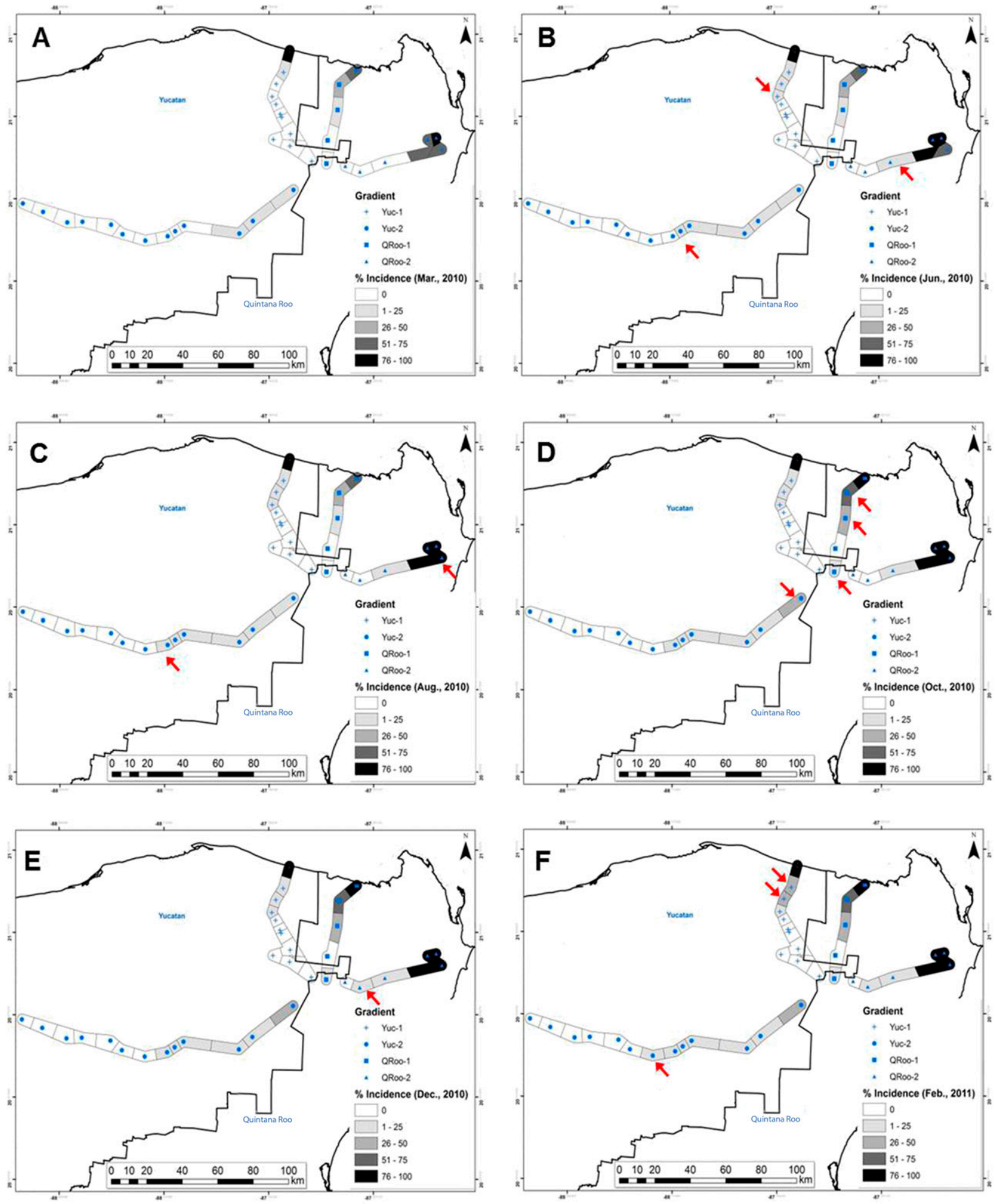

Fig. 1. Transect routes from a regional inoculum source (first reported outbreak) for the study of the long-range HLB gradients based on monthly assessment of disease incidence and severity from March 2010 to February 2011 at the Yucatan Peninsula, Mexico. Yucatan State, Yuc-1: from the locality El Cuyo to Popolnah, direction north-south (60 km); Yuc-2: Xcan-Kantunil, direction east-west (150 km). Quintana Roo State, QRoo-1: Chiquila-San Pedro, direction north-south (60 km); QRoo-2: Cancun-Esperanza, direction east-west $(80 \mathrm{~km})$. Transect routes on maps represent the extent of CLas dispersion over time on selected 6 months: March (A), June (B), August (C), October (D), December (E), and February (F). Gray color intensity represents HLB incidence according to the scale. Arrows indicate changes on HLB incidence over time. 
Spatial analysis of gradients. HLB incidences assessed at different distances from the initial outbreak showed the conformation of gradients in all transect routes (Fig. 3). Incidence was higher in the whole evaluation points as time progressed; hence, the gradients increased their disease intensity at each evaluation date (Figs. 1 and 3). However, the gradient distance was more influenced for the transect route orientation than the assessment time. In Yucatán State, the north-south route was shorter (Yuc-1, 10 to $25 \mathrm{~km}$ ) than the eastwest (Yuc-2, 60 to $82.6 \mathrm{~km}$ ), regardless of the high disease incidence $(100 \%)$ at the outbreak in the former case (Fig. 3A and B). In Quintana Roo State, both transect routes had similar effect on the gradient distance (40 to $43.9 \mathrm{~km}$ ) (Fig. 3C and D). In some monthly evaluations, there was slight change in the number of CLas-positive trees with respect to the previous month. In such cases, the gradient shape and parameters were similar (Table 1). The gradients depicted in the plots are those with contrasting disease intensity (Figs. 1 and 3).

Of the 3,250 total DC specimens collected, $63 \%$ were positive to $C$ Las. The longest gradient, Yuc-2, also presented the highest mean percent of $C$ Las-positive DC $(28.57 \%, n=92.8$ samples, standard deviation $=13.5 \%, P=0.05$ ). For the remaining transects, positive percentage ranged from 8 to $15 \%$ (standard deviation $=3.8$ to $5.3 \%$ ) (Fig. 4A). Percent of CLas-positive DC samples per assessing date, regardless of the transect routes, ranged from 12 to $26.5 \%$ (standard error $=5 \%$ ). The highest $C$ Las-positive DC peaks were observed in February and July, coinciding with vegetative shooting. However, there were no statistical differences among monthly samplings $(P \leq$ 0.05) (Fig. 4B). These peaks did not have an immediate effect on the respective HLB monthly gradients.

The traditional gradient models provided a good fit to data of last monthly assessment only (Table 2). The Gregory model fitted well the data of the Yucatan transect routes $\left(r^{2}=0.89\right.$ to 0.98$)$, whereas the negative-exponential fitted well data of the Yucatan and Quintana Roo transects ( $r^{2}=0.86$ to 0.98$)$ (Table 2$)$. Compared with the classical empirical models, the diffusion model provided a better fit to all HLB temporal gradients based on $R^{2}(0.90$ to 0.99$)$ and $P$-value $(0.05$ to 0.0001) (Table 2). Nevertheless, null-hypothesis tests of $a$ and $b$ parameters indicates that four transects of Yuc-1 (May to Aug.) and Yuc-2 (Sep. to Dec.), and one of QRoo-1 (Feb.), failed to reject the hypothesis of $b=1$, regardless of the $R^{2}$ value (0.92 to 0.94 ) (Table 2). The diffusion model provided a better fit to the data of 40 out of 48 gradients versus 6 out of 48 for the traditional models.

After 1 year, the longest distances of HLB spread ranged from 25 to $82.6 \mathrm{~km}$ depending on the transect route, and represented 38 to $66 \%$ of the whole transect distance; thus, the disease did not reach the end-route in any of the four transects during the period of study (Fig. 1). The east-west direction exhibited the longest disease gradients

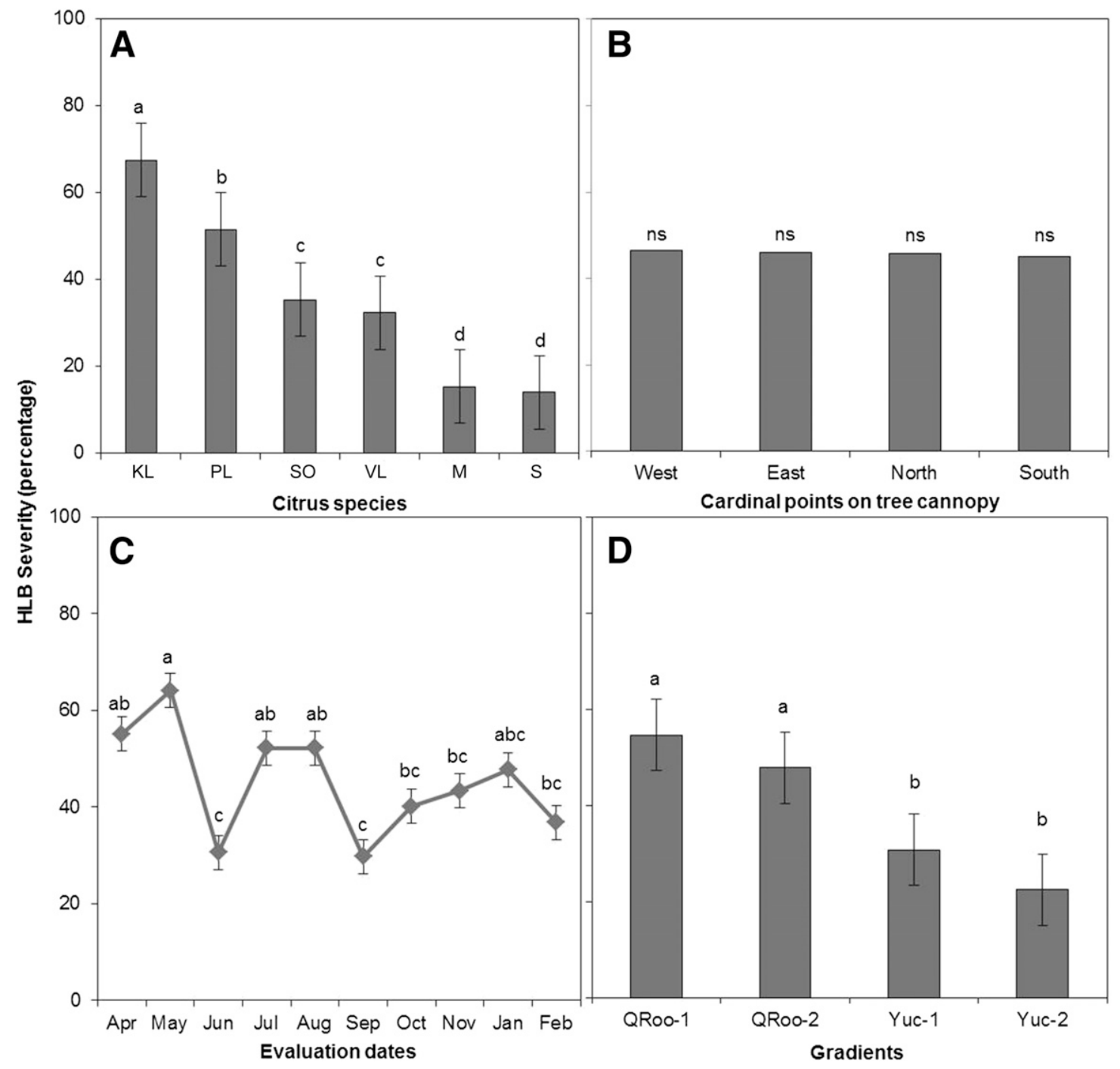

Fig. 2. Means of HLB severity (percentage of symptomatic tree canopy area) conditioned to citrus species (A): Key lime (KL), Persian lime (PL), sour orange (SO), Volkamerian lemon (VL), mandarin (M), and sweet orange (S); by gradients (B); cardinal point (C); and disease assessment dates (D), along four transect routes at Yucatan (Yuc) and Quintana Roo (QRoo) states, Mexico. For each variable, bars and lines with at least one letter in common are statistically similar (Tukey, $P<0.05$ ) and $n s$ is nonsignificant. The lines in the bars and points represent the standard deviation. 
(Yuc-2 $=82.6 \mathrm{~km}$ and average diffusion coefficient $D o=0.15$, and QRoo-2 $=43.9 \mathrm{~km}, D o=0.09)$ compared with the north-south direction (Yuc-1 $=25 \mathrm{~km}, D o=0.13$, and QRoo- $1=40 \mathrm{~km}, D o=$ 0.08) (Table 1, Fig. 1). The distance of the initial disease gradients (March assessment) varied from 0 to $16.7 \mathrm{~km}$ with respect to final gradients achieved a year later (Fig. 1). However, disease incidence and severity increased over time across the transect route. This was notably evident in the middle distance of transects. The annual average dispersion rate was higher in Yucatan than in Quintana Roo (Do $=0.14$ versus 0.08$)$.

Temporal analysis of gradients and regional occurrence. HLB temporal epidemic rates estimated at the longest gradient distance reached by $C$ Las throughout the vector dispersion, i.e., the speed of HLB epidemic at the front gradients, were well described by the Weibull model with $R^{2}=0.84$ to 0.98 (Fig. 5). Although the epidemic rates were low (0.008 to 0.002$)$, the gradient with the highest temporal epidemic rate was Yuc-2 $\left(1 / b=0.008, R^{2}=0.95\right)$, where $C$ Las dispersed $82.6 \mathrm{~km}$ from the initial focus; meanwhile, the lowest rate was Yuc-1 $\left(1 / b=0.002, R^{2}=0.84\right)$, and $25 \mathrm{~km} C$ Las dispersion (Fig. $5)$. The lowest temporal epidemic rates in Yuc-1, QRoo-1, and QRoo-2 were estimated for HLB incidences in the range of 100 to $63 \%$ at the source (distance $=0$ ). In Yuc-2, incidence was only 20\% (Fig. 3). Therefore, the HLB focus incidence was insufficient to determine the temporal epidemic rate or the disease gradient intensity. It also requires the potential effective inoculum that was estimated by the amount of CLas-positive insects (Fig. 4A). From 2009 to 2016, at the state level, the final accumulated number of diseased trees was 533 versus 403 in Yucatan and Quintana Roo, respectively.
Considering an estimated 20,200 ha of citrus, these occurrence levels indicates a low HLB regional prevalence in agreement with the low epidemic rates found on transects.

Development of $\boldsymbol{D}$. citri area-wide management approach. The HLB disease gradients adjusted to the diffusion model confirmed a spatial dependence from the first-reported outbreaks with different dispersion rates (Table 1, Fig. 3). Therefore, the range of gradient distances was used to define operational units for DC area-wide management strategy in Mexico, named Regional Areas for DC Control (ARCO in Spanish). This procedure was complemented with a regional risk factor, estimated based on epidemiological variables, e.g., cultivar susceptibility index, host density and relative abundance, agro-climatic effect on vector density, as well as quantity and foci distribution (Mora-Aguilera et al. 2014c). The risk factor (Risk $k_{\text {factor }}$ ) was calculated based on the weighted sum of all criteria listed above at the state and county levels. The proposed model is as follows:

$A R C O=\left(\left(\pi \times\left(\left(\operatorname{Grad}_{m a}+\operatorname{Grad}_{m}\right) / 2 \times \operatorname{Risk}_{\text {factor }}\right)^{2}\right) \times \mathrm{t}\right) \times 100$

where: $\operatorname{Grad}_{m a}=$ major gradient in $\mathrm{km}, \operatorname{Grad}_{m}=$ minor gradient in $\mathrm{km}$, estimated with the diffusion model; $t=$ time in months after a real or putative regional HLB outbreak; Risk $_{\text {factor }}=$ risk regional factor; $\pi$ is a constant value, and 100 is a conversion factor to hectares. The model is executed throughout Monte Carlo simulations at the state level, generating the number and size in hectares of ARCOs nationwide and for the operational year (Mora-Aguilera et al. 2014c).

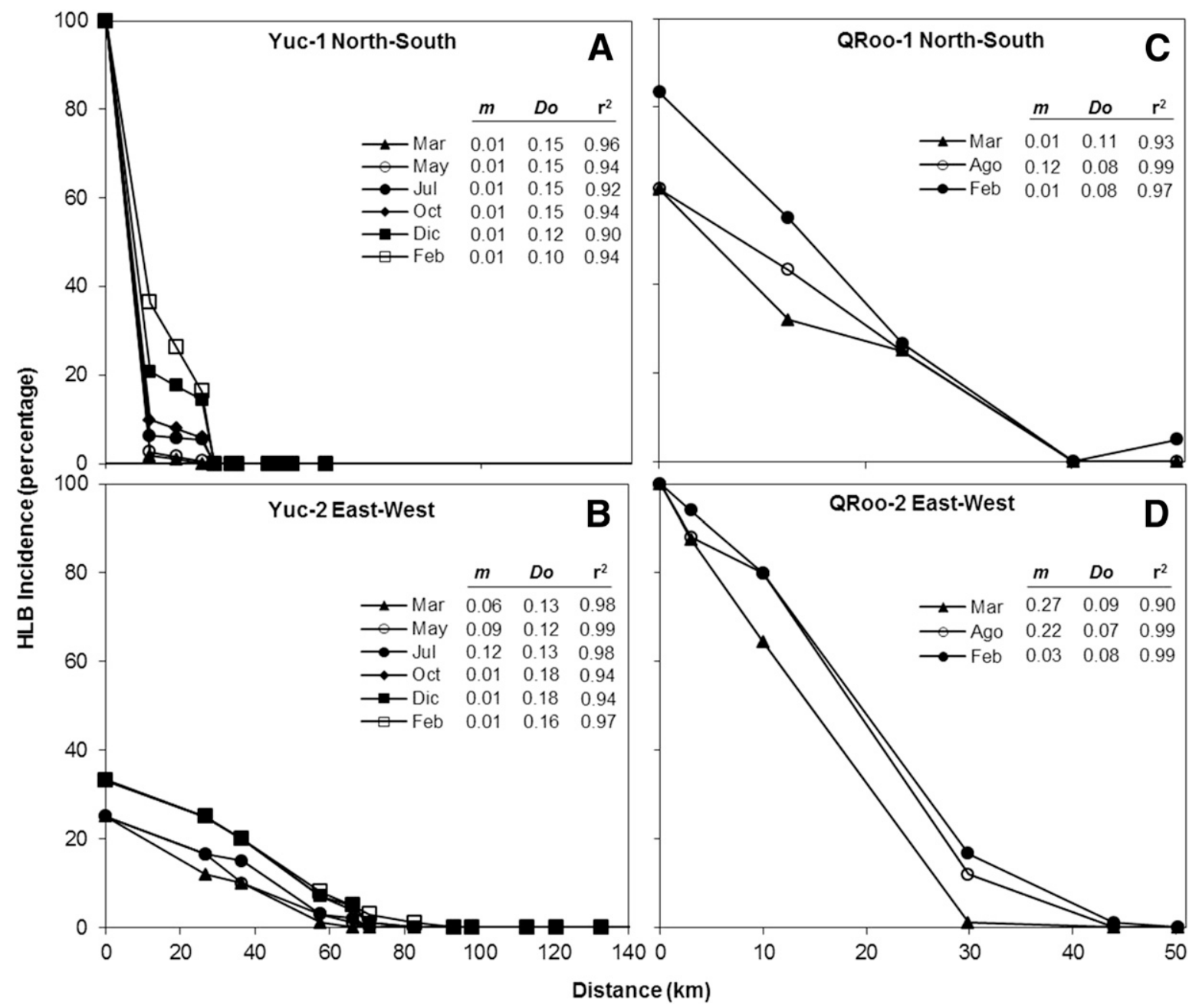

Fig. 3. Long distance gradients of HLB incidence (proportion of diseased trees) and distance among sampling areas (km), in Yucatan (Yuc) and Quintana Roo (QRoo) states, Mexico. Lines indicate gradients on selected evaluation dates of transect routes: Yuc-1 (A), Yuc-2 (B), QRoo-1 (C), and QRoo-2 (D). Diffusion model parameters: $m=$ shape of the curve, $D o=$ diffusion coefficient, and $r^{2}=$ coefficient of determination from simple linear regression of model-predicted and observed data. 


\section{Discussion}

The area-wide management approach for newly introduced diseases is relatively novel and the classical methods developed at the field scale are limited especially by the lack of spatio-temporal information for epidemics that spread at the regional scale (Mora-Aguilera et al. 2014a, b). This study provides the first quantitative evidence of the regional spread of HLB in Mexico, which was best described by a diffusion model (Murray 1989; Okubo 1980). This model is of utility to explain dispersal processes in epidemiological studies under the biological assumption of diffusivity due to inoculum pressure. The good fit of the diffusion model to the spatio-temporal HLB data assessed during a year from the first outbreaks reported at CuyoTizimin (July 2009), as well as Chiquila-Lázaro Cárdenas and Cancun (August 2009), suggests a spatial dependence from the disease outbreak (i.e., the focus or the inoculum source) for at least a year under the Yucatan Peninsula scenario. It also indicates the effect of primary inoculum for the region and the importance of early detection and removal of diseased trees in addition to DC PCR testing and vector control (Mora-Aguilera et al. 2014b, c; SENASICA 2016). In fact, in the Yucatan Peninsula, official efforts are underway to detect and eliminate diseased trees, principally on the rural settlements where the disease was mainly found. In addition, Tamarixa radiata (Hymenoptera:Eulophidae), an effective DC parasitoid, has been systematically released on backyards and abandoned orchards as part of the official efforts (SENASICA 2012, 2016). Our data suggests minimal effect of those actions on the regional gradients. However, in the long range, there was a noticeable effect in slowing the spread of CLas. The low intensity epidemics in Yucatan and Quintana Roo support this hypothesis (Fig. 5).

In Colima, a compact Key lime production area in the Mexican pacific region, spatial dependence was gradually lost 5 to 6 months after $C$ Las detection and HLB endemicity progressed due to secondary inoculum and reinfection (Mora-Aguilera et al. 2014c). The speed of HLB spread in the Pacific region was later associated to CLas Key lime higher vulnerability, compact host area (70 km range), and permanent exposure of diseased trees due to lack of removal (EsquivelChávez et al. 2012; Mora-Aguilera et al. 2014b; Robles-González et al. 2013). In addition, intensive chemical control probably reduces

Table 1. Parameters of the diffusion, negative-exponential, and Gregory models fitted to HLB incidence (proportion of diseased trees) data along four longdistance transects, being two in Yucatan (Yuc) and two in Quintana Roo (QRoo) states, Mexico. These transect originated from regional foci (first reported outbreak) and disease assessments were performed monthly from March 2010 to February 2011.

\begin{tabular}{|c|c|c|c|c|c|c|c|c|c|c|c|c|c|c|c|c|}
\hline \multirow[b]{3}{*}{ Date } & \multicolumn{16}{|c|}{ Diffusion model $^{\mathbf{a}}$} \\
\hline & \multicolumn{4}{|c|}{ Yuc-1 (north-south) } & \multicolumn{4}{|c|}{ Yuc-2 (east-west) } & \multicolumn{4}{|c|}{ QRoo-1 (north-south) } & \multicolumn{4}{|c|}{ QRoo-2 (east-west) } \\
\hline & $m$ & $n$ & Do & $P$ & $m$ & $n$ & Do & $P$ & $m$ & $n$ & Do & $P$ & $m$ & $n$ & Do & $P$ \\
\hline Mar & 0.01 & 31.91 & 0.15 & $<0.0001$ & 0.06 & 7.07 & 0.13 & $<0.0001$ & 0.01 & 16.39 & 0.11 & 0.0067 & 0.27 & 32.08 & 0.09 & 0.0464 \\
\hline Apr & 0.01 & 31.30 & 0.16 & $<0.0001$ & 0.01 & 5.33 & 0.25 & $<0.0001$ & 0.01 & 16.39 & 0.11 & 0.0067 & 0.08 & 33.45 & 0.08 & $<0.0001$ \\
\hline May & 0.01 & 30.80 & 0.15 & $<0.0001$ & 0.09 & 6.91 & 0.12 & $<0.0001$ & 0.12 & 18.34 & 0.08 & 0.0007 & 0.01 & 30.43 & 0.10 & $<0.0001$ \\
\hline Jun & 0.01 & 30.10 & 0.15 & $<0.0001$ & 0.12 & 6.47 & 0.13 & $<0.0001$ & 0.12 & 18.34 & 0.08 & 0.0007 & 0.01 & 28.43 & 0.11 & $<0.0001$ \\
\hline Jul & 0.01 & 30.10 & 0.15 & $<0.0001$ & 0.12 & 6.47 & 0.13 & $<0.0001$ & 0.12 & 18.34 & 0.08 & 0.0007 & 0.01 & 26.97 & 0.11 & $<0.0001$ \\
\hline Aug & 0.01 & 30.08 & 0.15 & $<0.0001$ & 0.13 & 6.73 & 0.11 & $<0.0001$ & 0.21 & 19.01 & 0.07 & 0.0003 & 0.22 & 31.15 & 0.07 & $<0.0001$ \\
\hline Sept & 0.01 & 30.02 & 0.15 & $<0.0001$ & 0.01 & 5.42 & 0.18 & $<0.0001$ & 0.01 & 22.19 & 0.05 & 0.0001 & 0.08 & 29.73 & 0.08 & $<0.0001$ \\
\hline Oct & 0.01 & 30.02 & 0.15 & $<0.0001$ & 0.01 & 5.28 & 0.18 & $<0.0001$ & 0.01 & 19.95 & 0.06 & 0.0003 & 0.08 & 29.73 & 0.08 & $<0.0001$ \\
\hline Nov & 0.01 & 29.54 & 0.12 & $<0.0001$ & 0.01 & 5.28 & 0.18 & $<0.0001$ & 0.01 & 19.95 & 0.06 & 0.0003 & 0.08 & 29.73 & 0.08 & $<0.0001$ \\
\hline Dec & 0.01 & 29.54 & 0.12 & $<0.0001$ & 0.01 & 5.28 & 0.18 & $<0.0001$ & 0.01 & 19.95 & 0.06 & 0.0003 & 0.03 & 29.26 & 0.08 & $<0.0001$ \\
\hline Jan & 0.01 & 29.54 & 0.10 & $<0.0001$ & 0.14 & 7.98 & 0.07 & $<0.0001$ & 0.01 & 19.95 & 0.06 & 0.0003 & 0.03 & 29.26 & 0.08 & $<0.0001$ \\
\hline Feb & 0.01 & 29.54 & 0.10 & $<0.0001$ & 0.01 & 5.57 & 0.16 & $<0.0001$ & 0.01 & 17.24 & 0.08 & 0.0018 & 0.03 & 29.26 & 0.08 & $<0.0001$ \\
\hline
\end{tabular}

\begin{tabular}{|c|c|c|c|c|c|c|c|c|c|c|c|c|c|c|c|}
\hline \multirow[b]{3}{*}{ Date } & \multicolumn{6}{|c|}{ Gregory model $^{\mathbf{b}}$} & \multicolumn{9}{|c|}{ Negative-exponential model } \\
\hline & \multicolumn{3}{|c|}{ Yuc-2 } & \multicolumn{3}{|c|}{ Yuc-1 } & \multicolumn{3}{|c|}{ Yuc-2 } & \multicolumn{3}{|c|}{ QRoo-1 } & \multicolumn{3}{|c|}{ QRoo 2} \\
\hline & $B_{0}{ }^{c}$ & $B_{1}$ & $P$ & $\boldsymbol{B}_{\boldsymbol{\theta}}$ & $B_{1}$ & $\boldsymbol{P}$ & $\boldsymbol{B}_{\boldsymbol{\theta}}$ & $B_{1}$ & $\boldsymbol{P}$ & $\boldsymbol{B}_{0}$ & $B_{1}$ & $\boldsymbol{P}$ & $\boldsymbol{B}_{0}$ & $B_{1}$ & $P$ \\
\hline Feb & 72.70 & 1.96 & 0.01 & 44.14 & 1.92 & 0.01 & 31.10 & 1.50 & 0.01 & 34.10 & 1.62 & 0.01 & 2.10 & 0.65 & 0.05 \\
\hline
\end{tabular}

${ }^{a} m=$ shape of the curve; $n=$ total population; $D o=$ diffusion coefficient; $P=$ significance (Murray 1989).

${ }^{\mathrm{b}}$ Gregory and negative-exponential models only fitted the February disease gradient.

${ }^{\mathrm{c}} B_{0}=$ the amount of disease incidence in the outbreak, $B_{1}=$ dispersion rate of Gregory and negative-exponential models.
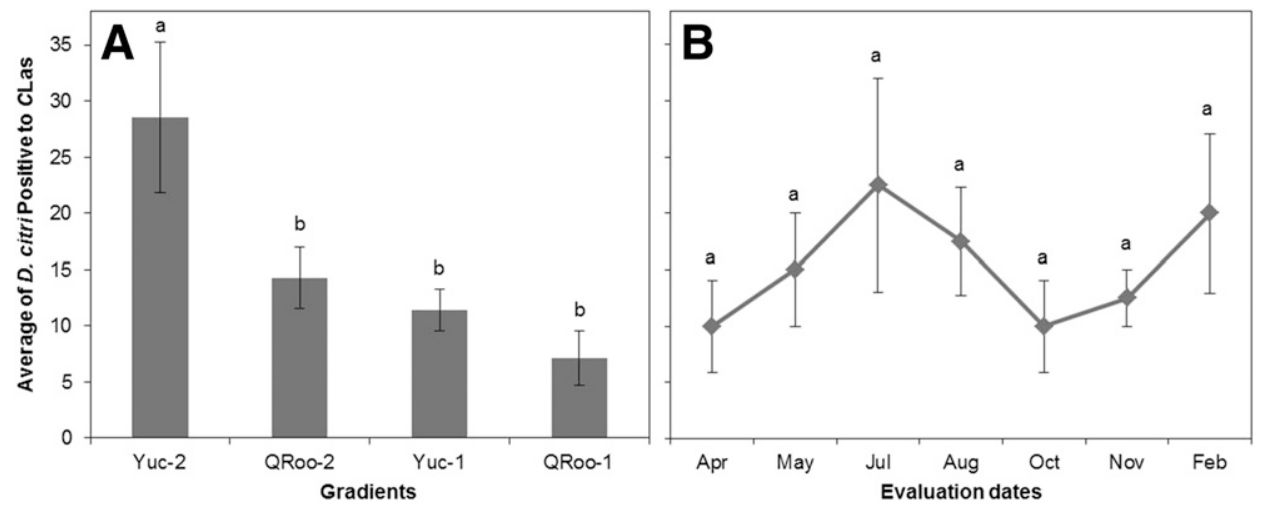

Fig. 4. Average of $D$. citri adults carrying CLas. A, Comparison among HLB long-range gradients at Yucatan (Yuc-1 and Yuc-2) and Quintana Roo (QRoo-1 and QRoo-2) states, Mexico. B, Comparison among evaluation dates. Bars and lines with at least one letter in common are statistically similar (Tukey, $P<0.05$ ). The lines in the bars and points represent the standard deviation. 
the benefit of biological control of DC, as opposed to the Yucatan Peninsula scenario (Cortez-Madrigal et al. 2014). Elsewhere, regional heterogeneity on epidemiological factors may also explain the variable long range CLas dispersal; this was inferred from systematic reports provided at county level after the disease outbreak (Salcedo et al. 2010). In such cases, directional asymmetric distances and various monthly dispersal rates $(\mathrm{km} / \mathrm{mo})$ of 8.9 to 12.5 (SP, Brazil), 17 to 34 (FL, U.S.A.), and 2 to 12.6 (Colima, Mexico) were found (Mora-Aguilera et al. 2014c). These rates are higher than those estimated in this work ( 2.6 to $6 \mathrm{~km} / \mathrm{mo}$ ), suggesting that further studies should be conducted for the purpose of surveillance, risk analysis, and area-wide management (Mora-Aguilera et al. 2014a, b).

Since CLas is a pathogen vectored by Diaphorina citri, this is the principal spreading factor upon pathogen detection in a disease-free region. The gradients described in this study suggest that primary inoculum spread by the vector rapidly covers a large area depending on several factors. The HLB focus intensity, i.e., the disease intensity (both incidence and severity) considered as the potential inoculum charge is apparently insufficient to influence the gradient intensity. Yuc-2 showed the lowest focus intensity; nonetheless, it showed higher gradient intensity with the longest gradient. Anthropogenic activity, host spatial connectivity, vector density, and wind dominance appear to play a significant role. Yuc-2 was established on a major citrus-producing area with east-west dominant winds and higher positive-DC numbers, whereas the remaining transect routes were associated with scattered producing areas and rural settlements with backyard citrus trees used for culinary or ornamental purposes, including Murraya paniculata, a recognized CLas alternate host (Walter et al. 2012). Interestingly, the highest average HLB severity and incidence was observed in Quintana Roo gradients, suggesting higher inoculum pressure. However, the average diffusion rate was lower $(D o=0.08)$ with respect to Yucatan $(D o=0.14)$. Higher

Table 2. Agreement test based on the intercept $(a)$ and slope $(b)$ of simple linear regression between actual versus predicted HLB incidence (proportion of disease trees) data by the diffusion, Gregory and negative-exponential models fitted to disease gradients along four transect routs assessed monthly from March 2010 to February 2011 in Yucatan (Yuc) and Quintana Roo (QRoo), Mexico

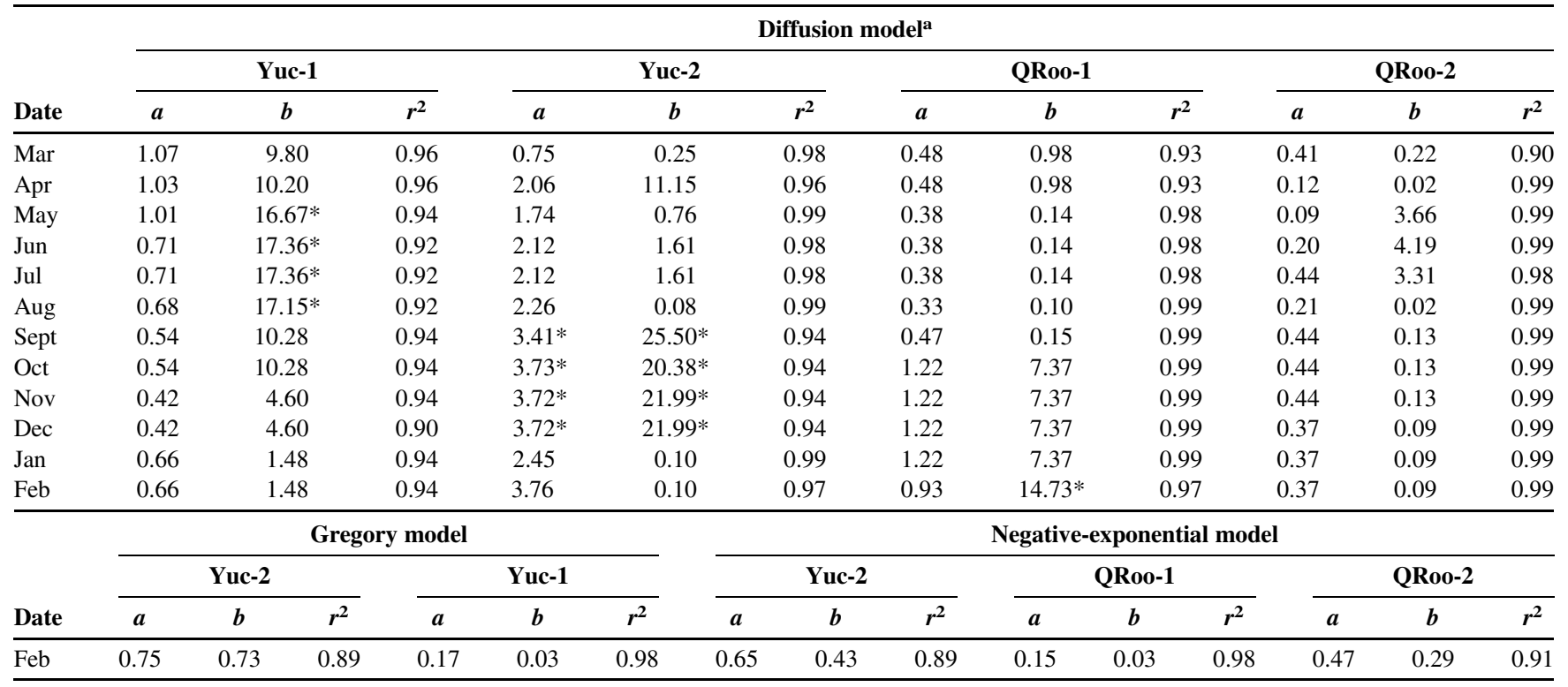

a An asterisk (*) indicates parameters in which the null hypothesis $(\mathrm{a}=0$ or $\mathrm{b}=1)$ was rejected by the $t$ test, $P<0.01$.
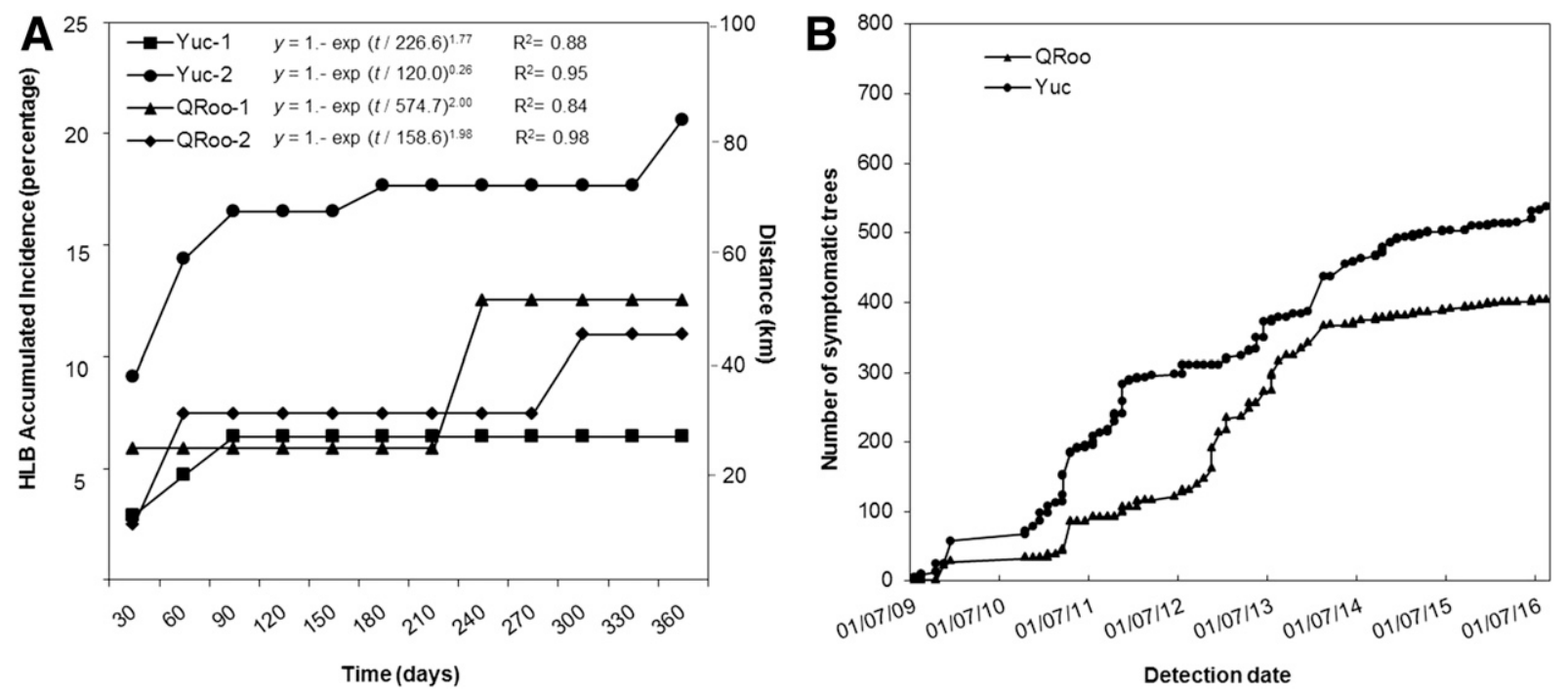

Fig. 5. A, Temporal progress of HLB incidence data over 12 months and respective epidemic rates estimated at the longest gradient distance in Yucatan and Quintana Roo states: Yuc-1, Yuc-2, QRoo-1, and QRoo-2. Epidemic rates $(1 / b)$ were estimated using the Weibull model $\left(y=1-\exp [t / b]^{\mathrm{C}}\right)$. B, Accumulated number of HLB symptomatic citrus trees in Yucatan (Yuc) and Quintana Roo (QRoo) states, Mexico, from 2009 to 2016 
disease severity in Quintana Roo transects was associated with high prevalence of sour citrus species, which were more vulnerable to $C$ Las than sweet orange, as previously reported (Esquivel-Chávez et al. 2012). Plant flush dynamics and temperature may explain a temporal variation in disease severity found in this work, and thus on inoculum availability. However, these factors apparently did not affect monthly diffusion rates (Table 1). Although it has been documented that summer temperature suppresses symptoms (Bassanezi et al. 2013a), we found that the positive-DC population increased during spring and summer, indicating a lag effect of symptom expression upon transmission, a well-recognized epidemiological effect on vector-borne diseases (Mora-Aguilera 1995).

The spatio-temporal patterns of HLB gradients and the directional dependence of the disease outbreak area were used to determine the range of longest (east-west) and shortest (north-south) distance gradients, which confirmed the asymmetric disease gradients in longrange scenarios due to regional heterogeneity. Previously, for another vector-borne disease, the symmetric and asymmetric behavior seemed to depend on the spatial scale and the dominant winds in the Yucatan Peninsula (Góngora-Canul et al. 2004; Mora-Aguilera et al. 2014b; 2017). The symmetric gradients at the field level can be explained by homogeneous conditions, such as regular plant density, standard crop management, and uniform microclimate (Pérez-Hernández et al. 2004).

To the best of authors' knowledge, this is the first use of a flexible diffusion model (Murray 1989; Okubo 1980) to describe plant disease gradients at the regional scale. The gain from using a single model to fit a family of curves is the capability to compare dispersion rates directly; in the case of the diffusion model, comparison was based on the estimated Do parameter. This model resembles the Weibull model, which is broadly used to describe temporal disease progress (Mora-Aguilera et al. 1996; Pennypacker et al. 1980). However, the epidemiological interpretation of $m, n$, and $D o$ parameters require further specific studies for a meaningful biological interpretation (Murray 1989; Okubo 1980). For instance, whether the $n$ parameter is a good estimator of focus intensity or a simple fit factor needs to be further addressed as well as a sound statistical test relating these parameters should be developed. In our data, $m$ appears to be more sensitive than Do parameters ranging from 0.01 in short and step gradients as in Yuc-1, up to 0.27 in shallow curve gradients as in the rest. In Okubo's interpretation, $m<1$ is related to a leptokurtic population randomly distributed from a multiplicative source (Okubo 1980). In the HLB scenario, it can be interpreted as a strong distance dependence of the inoculum focus at an early epidemic stage; thus, more suitable for primary inoculum control with diseased tree removal. An $m>1$ refers to a platykurtic distribution that can be inferred as dependence loss due to secondary inoculum effect causing the HLB endemic condition such as in Colima State (Mora-Aguilera et al. 2014c). A proposed concept, based on these biological interpretations, is the establishment threshold, referring to the $m$-value in which the spatial dependence is lost due to putative primary and secondary inoculum equilibrium; consequently, the pathogen succeeds in establishing upon its arrival in a region. This concept is useful to develop a comprehensive system for HLB management applying the prevention and protection principles (Mora-Aguilera et al. 2014b, c). This idea has been used to identify risky regions in which ARCO is a valid approach.

The superior fit of the diffusion model compared with the traditional disease gradient models was expected due to its flexible structure that allows fitting a family of gradient shapes derived of the spatio-temporal dispersion dynamics (Mora-Aguilera et al. 2014b). The classical, nonflexible models can fairly fit gradients measured at the plot level as shown for coconut lethal yellowing and potato purple top (Góngora-Canul et al. 2004 ; Mora-Aguilera 1995; MoraAguilera et al. 2014b), but their use for scales above the field level, as shown here, are not recommended. In fact, if classical models are fitted through linearization, the structure of the gradient, particularly the asymptotic behavior, is lost. Moreover, their empirical nature means that the parameters my not have a direct biological interpretation (Campbell and Madden 1990).

Spatial gradient analyses are less commonly found compared with temporal or spatial pattern studies (Bassanezi et al. 2005; Campbell and Madden 1990; Gottwald 2010; Pérez-Hernández et al. 2004; Shen et al. 2013), and this is probably because the studies aim at describing epidemics rather than preventing them. In addition, study of epidemics has long been focused at the plot level, constraining the decision-making required to support area-wide disease management, a current tendency on regulated plant pathogens (Mora-Aguilera et al. 2014a, b, c; Santivañez et al. 2014). For instance, in coconut lethal yellowing, regional and intraplot disease gradients were used for weighted sampling in early disease detection and establishing quarantine zones (Mora-Aguilera et al. 2017). In HLB, current official decisions on the establishment of area-wide management of DC (ARCO) are presently performed in Mexico, based on the information generated in this study as well as probable risk scenarios (Mora-Aguilera et al. 2014c; Salcedo et al. 2010; Torres-Pacheco et al. 2013). The area-wide size and location of ARCOs are not based on empirical assumptions (Bové 2012), restricted spatial data obtained at plot level (Gottwald et al. 2014), or operational criteria (Rogers et al. 2011). The ARCO quantitative approach complements the biological support provided by regional studies of vector control and removal of symptomatic trees (Bassanezi et al. 2013a, b). The ARCO approach is currently operated in 23 citrus-producing Mexican states with an estimated governmental cost of US\$32.1 million for the last 3 years. The area-wide management has expanded considerably over the years, from 120,299 (22.6\% of national citrus growing regions) in 2015 , to $169,993(31.8 \%$ ) in 2016, and 276,050 ha (51.7\%) in 2017. Regardless of the DC distribution (Torres-Pacheco et al. 2013), ARCO has contributed to delay $C$ Las spread, mitigating HLB impact mainly on sweet citrus species (SENASICA 2016, 2017). This comprehensive approach has also allowed to support HLB phytosanitary policies and to encourage its adoption in the Mexican plant health system (SENASICA 2012, 2016).

\section{Acknowledgments}

The first author thanks COLPOS and CONACYT for his Mexican MSc Scholarship. We also thank the Plant Health State Committee of Yucatan and Quintana Roo states for technical assistance, especially to Ricardo Munguía, Antonio Novelo, Jorge Velázquez, and Pedro López. This research was funded by SENASICA-DGSV and FONSEC-SAGARPA-CONACYT 2009-108591.

\section{Literature Cited}

Bassanezi, R. B., Belasque, J., Jr., and Montesino, L. H. 2013a. Frequency of symptomatic trees removal in small citrus blocks on citrus huanglongbing epidemics. Crop Prot. 52:72-77.

Bassanezi, R. B., Busato, L. A., Bergamin Filho, A., Amorim, L., and Gottwald, T. R. 2005. Preliminary spatial pattern analysis of huanglongbing in São Paulo, Brazil. Pages 341-355 in: Proceedings of the 16th Conference of the International Organization of Citrus Virologists, Riverside, CA.

Bassanezi, R. B., Montesino, L. H., Gimenes-Fernandes, N., Yamamoto, P. T., Gottwald, T. R., Amorim, L., and Bergamin Filho, A. 2013b. Efficacy of area-wide inoculum reduction and vector control on temporal progress of huanglongbing in young sweet orange plantings. Plant Dis. 97:789-796.

Bové, J. M. 2012. Huanglongbing and the future of citrus in Sao Paulo, State, Brazil. J. Plant Pathol. 94:465-467.

Campbell, C. L., and Madden, L. V. 1990. Introduction to Plant Disease Epidemiology. John Wiley and Sons, New York., 532 pp.

Cortez-Madrigal, H., Sánchez-Saavedra, J. M., Díaz-Godinez, G., and MoraAguilera, G. 2014. Enzymatic activity and pathogenicity of entomopathogenic fungi from Central and Southeastern Mexico to Diaphorina citri (Hemiptera: Psyllidae). Southwest. Entomol. 39:491-502.

Dellaporta, S. L., Word, J., and Hicks, J. B. 1983. A plant DNA minipreparation: Version II. Plant Mol. Biol. Report. 1:19-21.

Esquivel-Chávez, F., Valdovinos-Ponce, L., Mora-Aguilera, G., Gómez-Jaimes, R., Velázquez-Monreal, J. J., Manzanilla-Ramírez, M. A., Flores-Sánchez, J. L., and López-Arroyo, J. I. 2012. Histological analysis of sour citrus and sweet orange leaves with symptoms caused by Candidatus Liberibacter asiaticus. Agrociencia 46:769-782.

Flores-Sánchez, J. L., Mora-Aguilera, G., Loeza-Kuk, E., López-Arroyo, J. I., Domínguez-Monge, S., and Acevedo-Sánchez, G. 2015. Yield loss caused by Candidatus Liberibacter asiaticus in Persian lime, in Yucatan Mexico. Mex. J. Phytopathol. 33:195-210.

Góngora-Canul, C. C., Pérez-Hernández, O., Pech-Cauich, O., EscamillaBencomo, J. A., and Mora-Aguilera, G. 2004. Gradientes de diseminación del amarillamiento letal en cocotero (Cocos nucifera L.) en Sisal Yucatán, México. Rev. Mex. Fitopatol. 22:370-376.

Gottwald, T., Luo, W., Riley, T., and Parnell, S. 2014. Edge effect and huanglongbing. J. Cit. Pathol. 1:126-127. 
Gottwald, T. R. 2010. Current epidemiological understanding of citrus huanglongbing. Annu. Rev. Phytopathol. 48:119-139.

Hall, D. G., Richardson, M. L., Ammar, E., and Halbert, S. E. 2013. Asian citrus psyllid, Diaphorina citri, vector of citrus huanglongbing disease. Entomol. Exp. Appl. 146:207-223.

Jesús, W. C., Jr., Pozza, E. A., Vale, F. X. R., and Mora-Aguilera, G. 2004. Análise Temporal de Epidemias. Pages 127-191 in: Epidemiologia Aplicada ao Manejo de Doenças de Plantas. F. X. R. Vale, W. C. Jesús Jr., and L. Zambolim, eds. Perffil Editora, Brasil.

Li, W., Hartung, J. S., and Levy, L. 2007. Evaluation of DNA amplification methods for improved detection of 'Candidatus Liberibacter species' associated with citrus Huanglongbing. Plant Dis. 91:51-58.

Mora-Aguilera, G. 1995. Aphid vector dynamics and temporal and spatial characterization of watermelon virus epidemics. Ph.D. Thesis. University of Florida. Online, retrieved from https://openlibrary.org/books/OL25924428M.

Mora-Aguilera, G., Robles, G. P. L., González, G. R., Hernández, N. G., López, M. M. Y., Macías, C. P., López, B. J. A., and Acevedo, S. G. 2017. La Campaña Contra el Amarillamiento Letal del Cocotero. SENASICA CP, México.

Mora-Aguilera, G., Acevedo-Sánchez, G., Flores-Sánchez, J., Hernández, R., González-Gómez, R., and Robles-García, P. 2014a. Regional epidemiology: a new frontier and challenge in plant pathology. Pages 1-5 in: Proceedings of the 47th Congress of Phytopathology of Brazil, 17-22 August 2014, Londrina, Brazil.

Mora-Aguilera, G., Flores-Sánchez, J., Acevedo-Sánchez, G., Domínguez-Monge, S., Oropeza-Salin, C., González-Gómez, R., and Robles-García, P. 2014b. Epidemiological surveillance and current status of lethal yellowing coconut, potato purple top and citrus huanglongbing (HLB) in Mexico. Mex. J. Phytopathol. 32:120-131.

Mora-Aguilera, G., Nieto-Angel, D., Campbell, C. L., Téliz, D., and Garcia, E. 1996. Multivariate comparison of papaya ringspot epidemics. Phytopathology 86:70-78.

Mora-Aguilera, G., Robles-García, P., López Arroyo, J. I., Velázquez Monreal, J., Flores-Sánchez, J., Acevedo-Sánchez, G., Domínguez-Monge, S., and González-Gómez, R. 2014c. Current situation and prospects for management of citrus HLB. Mex. J. Phytopathol. 32:108-119.

Murray, J. D. 1989. Mathematical Biology. Springer-Verlag, Berlin.

Okubo, A. 1980. Diffusion and Ecological Problems: Mathematical Models. Springer-Verlag, Berlin.

Pennypacker, S. P., Knoble, H. D., Antle, C. D., and Madden, L. V. 1980. A flexible model for studying plant disease progression. Phytopathology 70:232-235.

Pérez-Hernández, O., Góngora-Canul, C. C., Medina-Lara, M. F., Oropeza-Salín, C., Escamilla-Bencomo, J. A., and Mora-Aguilera, G. 2004. Patrón espaciotemporal del amarillamiento letal en cocotero (Cocos nucífera L.) en Yucatán, México. Rev. Mex. Fitopatol. 22:231-238.
Robles-González, M. M., Velázquez-Monreal, J. J., Manzanilla-Ramírez, M. A., Orozco-Santos, M., Medina-Urrutia, V. M., López-Arroyo, J. I., and FloresVirgen, R. 2013. Síntomas del huanglongbing (HLB) en limón mexicano (Citrus aurantifolia) y su dispersión en el estado de Colima, México. Rev. Chapingo Ser. Hortic. 19:15-31.

Rogers, M. E., Stansly, P. A., and Stelinski, L. L. 2011. Citrus Health Management Areas (CHMAs): Developing a Psyllid Management Plan. University of Florida, IFAS Extension, Gainesville, FL. Online publication: http://www.crec.ifas.ufl.edu/extension/chmas/PDF/CHMA_spray\%20plan_ 10_11_10.pdf

Salcedo, B. D., Hinojosa, R., Mora-Aguilera, G., Covarrubias, I., De Paolis, J. R. F., Mora, S., and Cíntora, C. 2010. Evaluación del Impacto Económico de Huanglongbing (HLB) en la Cadena Citrícola Mexicana. Instituto Interamericano de Cooperación para la Agricultura (IICA). México. Online publication: http:// legacy.iica.int/Esp/regiones/norte/mexico/Publicaciones\%20de\%20la\%20Oficina/ B2009e.pdf

Santivañez, C. T., Vernal, H. P., Mora-Aguilera, G., Diaz, P. G., and López Arroyo, J. I. 2014. Marco Estratégico para la Gestión Regional del Huanglongbing en América Latina y el Caribe. FAO, Rome, Italy. Online publication: http://www.fao.org/3/a-i3319s.pdf

SENASICA. 2012. Protocolo para establecer Áreas Regionales de Control de Huanglongbing y el Psilido Asiático de los Cítricos (ARCOs). Servicio Nacional de Sanidad, Inocuidad y Calidad Agroalimentaria (SENASICA), México, D. F. Online publication: http://www.siafeson.com/sitios/simdia/docs/protocolos/ ProtocoloparaestablecerAreasRegionalesARCOSDICIEMBRE2012.pdf

SENASICA. 2016. Acciones contra el Huanglongbing y su vector en México. Report of December, 2016. Online publication: http://www.gob.mx/cms/uploads/ attachment/file/186023/12_Informe_nacional_HLB_diciembre.pdf

SENASICA. 2017. Vigilancia del Huanglongbing. Online, retrieved from http:// sinavef.senasica.gob.mx/SIRVEF/HLB.aspx

Shen, W., Halbert, S. E., Dickstein, E., Manjunath, K. L., Shimwela, M. M., and van Bruggen, A. H. C. 2013. Occurrence and in-grove distribution of citrus huanglongbing in north central Florida. J. Plant Pathol. 95:361-371.

Torres-Pacheco, I., López-Arroyo, J. I., Aguirre-Gómez, J. A., Guevara-González, R. G., Yánez-López, R., Hernández-Zul, M. I., and Quijano-Carranza, J. A 2013. Potential distribution of Diaphorina citri (Hemiptera: Psyllidae) vector of huanglongbing in Mexico. Fla. Entomol. 96:36-47.

Trujillo-Arriaga, J. 2010. Situación actual, regulación y manejo del HLB en México. Pages 1-2 in: Proceedings of the 2nd International Workshop on Citrus Huanglongbing and the Asian Citrus Psyllid, 19-23 July 2010, Mérida, Yucatán, Mexico.

Walter, A. J., Duan, Y. P., and Hall, D. G. 2012. Titers of 'Ca. Liberibacter asiaticus' in Murraya paniculata and Murraya-reared Diaphorina citri are much lower than in citrus and citrus-reared psyllids. HortScience 47:1449-1452. 